\title{
DIEGO DE URREA Y ALGÚN TRADUCTOR MÁS: EN TORNO A LAS VERSIONES DE LOS "PLOMOS"
}

\author{
FERNANDO RODRÍGUEZ MEDIANO \\ y MERCEDES GARCÍA-ARENAL \\ CSIC, Madrid
}

En su célebre estudio sobre el arabismo español, James T. Monroe aseguraba que, durante el siglo XVII, los estudios árabes en España sufrieron un eclipse, al que no sobrevivió ninguna obra significativa. Monroe sólo cita una historia de la España musulmana, obra de Marco Obelio Citeroni ${ }^{1}$, cuyo título era Suma que trata del tiempo cuando los mahometanos ganaron a África, y cómo después pasaron a España... vuelta de arábigo en romance ${ }^{2}$. Según Monroe, puede encontrarse un pequeño rastro de una cierta continuidad de los estudios árabes durante ese período en el Tesoro de la lengua castellana o española de Sebastián de Covarrubias que, para las etimologías árabes, había consultado al intérprete Diego de Urrea, así como las obras de Fray Francisco de Guadix. Ninguno de los dos, sin embargo, había llegado a publicar sus escritos, lo que confirmaría la falta general de conocimiento sobre el árabe característica del período.

El juicio de Monroe parece excesivo. El final del s. XVI y el comienzo del XVII constituyen un período en el que la confluencia de distintas circunstancias hizo que el conocimiento del árabe cobrase una relevancia especial. Las relaciones con el norte de África tenían una importancia política y estratégica crucial para la España de la época, tanto por la rivalidad con el Imperio Otomano, como por lo que tenía que ver con Marruecos. Una de las facetas de esas relaciones era, por ejemplo, la cuestión de los moriscos, presente en acontecimientos tan espectaculares como la Guerra de las Alpujarras o los Plomos del Sacromonte. A este interés inmediato por cuestiones rela-

\footnotetext{
${ }^{1}$ Monroe, J. T., Islam and the Arabs in Spanish Scholarship (Sixteenth Century to the Present), Leiden, 1970, 23.

2 Menéndez Pelayo, M., La ciencia española, ed. Enrique Sánchez Reyes, 3 vols. Santander, 1954, vol. III, 124.
}

Al-Qanțara XXIII, 2 (2002) 499-516 
tivas al Islam y al norte de África había que añadir, además, un interés histórico y arqueológico por el pasado peninsular, cuyo componente árabe era visible no sólo en la permanencia de una población de origen musulmán, sino también en la existencia de ruinas, monumentos e inscripciones, vestigios materiales que había que integrar en la construcción de una historia de España ${ }^{3}$. Todas estas circunstancias están presentes en la actuación de los traductores de árabe de la época, como intentaremos mostrar a partir del caso concreto de los Libros Plúmbeos. Dentro de la larga polémica suscitada desde la aparición de las primeras reliquias en 1588, la cuestión de la traducción y, por lo tanto, de la calidad y fiabilidad de los traductores, se convierte en el punto axial. Desde finales del siglo XVI y durante todo el XVII, no hubo persona conocedora de la lengua árabe en España primero, luego en el Vaticano ${ }^{4}$, que no fuera puesta en algún momento a contribución de las tareas de traducción promovidas principalmente por el Arzobispo Pedro de Castro. Las personalidades más conocidas, a las que incluso se ha llegado a atribuir la autoría al menos parcial de los inventos son, claro está, los moriscos Alonso del Castillo ${ }^{5}$ y Miguel de Luna ${ }^{6}$. Por otros méritos además del de traductor, son también bien conocidos Benito Arias Montano y, más recientemente, Aḥmad b. Qāsim al-Haŷarī ${ }^{7}$. Pero hubo muchos más: H. Ecker, en su contribución a esta misma sección monográfica, cuenta hasta diecinueve traductores. Aquí queremos trazar la trayectoria de uno de los más importantes y menos conocido de éstos, el intérprete real y catedrático de Alcalá de Henares, Diego de Urrea, traductor oficial también del turco, persa y tártaro.

Aunque de origen y formación muy diferente a Alonso del Castillo, por ejemplo, su trayectoria profesional tiene paralelos con la de

3 Véase, por ejemplo, el artículo de Heather Ecker en este mismo número.

${ }^{4}$ Como es el caso de fray Bartolomé Pectorano, cuya traducción al latín se conserva en la British Library. Sobre todas estas cuestiones, véase el magistral estudio de G. Morocho Gayo en Pedro de Valencia. Obras completas, vol. IV, León, 1999, 143-359.

5 Cabanelas, D., El morisco granadino Alonso del Castillo, Granada, 1965.

6 Márquez Villanueva, F., "La voluntad de leyenda de Miguel de Luna", en El problema morisco (desde otras laderas), Madrid, 1992, 45-97, y el estudio preliminar de L. Bernabé Pons a la edición facsímil de la Historia verdadera del Rey Don Rodrigo, de Miguel de Luna, Granada, 2001

7 Véase el estudio biográfico en la introducción de la edición y traducción inglesa, por van Koningsveld, Wiegers y al-Samarrai, del Kitāb Nāssir al-dīn 'alä 'l-qawm al-käfirin, Madrid, 1997. 
éste: ambos fueron intérpretes reales y dedicaron buena parte de su actividad profesional a la traducción de las cartas enviadas al rey de España por los sucesivos sultanes marroquíes, ambos participaron de las tareas de catalogación de la Biblioteca de El Escorial y además de traductores, fueron informadores (espías, podríamos decir) e intermediarios al servicio de la Corona: Castillo en la Guerra de las Alpujarras; Urrea, en el asunto de la cesión de Larache. Es decir que compaginaron tareas académicas con un profundo envolvimiento en los acontecimientos de su tiempo. Urrea, además, fue uno de los primeros catedráticos de árabe que hubo en una universidad española. Las trayectorias personales y profesionales de estos intépretes y traductores, a menudo pertenecientes a un mundo de frontera, a una vida azarosa $o$ aventurera, se encuentran de algún modo en los inicios del arabismo científico en España surgido al amparo del Humanismo. De ahí, en nuestra opinión, el interés que presenta el intentar dilucidar su formación, sus conocimientos y los usos a cuya contribución les puso la Corona española.

De la vida de Diego de Urrea hemos conseguido recoger una cantidad de datos variados que jalonan una trayectoria sumamente interesante. Juan Luis de Rojas le dedica una amplia noticia que merece ser recogida in extenso ${ }^{8}$ : Diego de Urrea "es natural a lo que se dize del Reyno de Nápoles: tomáronle los Turcos tan niño, que le criaron en su ley y costumbres muchos años y en ellos atendió a la lengua Arábiga y Turca, que escreviéndolas y leyéndolas las hizo más suyas que si fueran naturales: y estudió Gramática Arábiga, la Lógica y Philosophía con muchas ventajas, enterándosse muy bien del Alcorán y su maldita Theología, por tanto estremo, que no uvo Moro que lo aventajasse, y aun después en la Almahala de Muleixeque se ordenó que nadie disputasse con él, como se dirá. Con esto dizen que tuvo buen lugar con el gran Turco, pero viviendo en perpetuo miedo de la vida, como andan todos los que de zerca siguen aquella injusta Corte, en fin se escapó, dize que con grandes riquezas; él llegó sin ninguna a Cicilia [por Sicilia] donde el conde de Alba de Liste, que era Virrey en ella, le amparó y abrigó, haziéndole enseñar de nuevo y vistiéndole y teniéndole en su casa de donde le embiavan a la Compañía de Jesús a deprender un poco de latín, que supo brevemente. De allí vino a Espa-

${ }^{8}$ Rojas, J. L. de, Relaciones de algunos sucesos postreros de Berberia, Lisboa, 1613 , f. $63 \mathrm{v}$. 
ña con el Conde o no sé si antes para servir de lengoa y traduzir las cartas Turcas y Moras en que cierto es eminente. Sirvió assí muchos años, criando un discípulo, que según el dize, en letra y intelligencia ha salido tan bueno como él (él asiste en la Corte). Con eso y algunas mercedes que por tiempo se le hicieron, se casó y, teniendo ya licencia y estando de partida para Nápoles, adonde llevava casi cien ducados de sueldo al mes, le embargaron la persona para esta plática de Muleixeque, en que se detuvo más de un año, de que dos meses últimos trabajó como se dirá con peligro y cuidado". El discípulo mencionado por Rojas es Francisco de Gurmendi ${ }^{9}$, que participó también en las traducciones de los Plomos.

Los primeros documentos que mencionan a Diego de Urrea aparecen entre los fondos de Sicilia conservados en el Archivo de Simancas y confirman y amplían esta noticia de Juan Luis de Rojas, aunque la varían también un poco: Diego de Urrea no parece haberse escapado voluntariamente al lado cristiano, sino que fue capturado con el séquito de Hasan Aga, "virrey de Argel", de quien era secretario, en una nave que iba a Estambul. En las "Relaciones de causas" de la Inquisición de Sicilia se conserva noticia de su reconciliación, en octubre de 1589, en estos términos: "Diego de Urrea, y en turquesco Morato, de edad de treinta años, secretario de Çenaga, estando en una galera suya que dió al trabés en la ysla de la Pantelería, fue preso de christianos y traydo a esta çiudad [Palermo] fue conoçido de algunos que le habían visto allí por ser hombre de los más leydos y letrados de Berbería; spontáneamente vino a este tribunal y dixo que siendo de çinco o seis años fue preso de moros en Calabria y llebado a Berbería, le retajaron y se crió en la seta de Mahoma con crehençia de ella porque de la ley evangélica no tubo ynstructión ni conocimiento. Ansí se dio orden a personas religiosas que le ynstruyessen sin hazer más diligencias" ${ }^{10}$. Esta instrucción debió ser apadrinada por el virrey Alba de Liste, quien, como dice Rojas discretamente, "le hizo enseñar de nuevo".

Una carta de 1591 enviada a la corte por Alba de Liste ${ }^{11}$, dice: "Havrá años que entre otros esclavos que se ganaron en la Pantalera

\footnotetext{
9 Sobre el cual véase Magnier, G., "The dating of Pedro de Valencia's Sobre el pergamino y láminas de Granada”, Sharq Al-Andalus, 14-15 (1997-98) 353-373, en especial 360 y ss.

10 Archivo Histórico Nacional, Inquisición, Sicilia, Libro 898, f.359. 1591 .

${ }_{11}$ Diego Enríquez de Guzmán, conde de Alba de Liste, virrey de Sicilia entre 1585 y
} 
haviendo llegado allí una galera turquesca, yva parte de la casa de Asan Aga a Constantinopla, se tomó un secretario que entonces se llamava Morato Aga, Diego de Urrea, hijo del capitán Moreto calabrés ${ }^{12}$, natural de Tropea, el qual fue captivo de edad de seis años, persona muy estudiosa y plática en las lenguas persiana, arábica, turquesca y morisca. Sirvió a Luchalí en el mismo officio que al Assan, y tiene la noticia de sus designios y traças a la empresa de Fez, que mandará entender Vuestra Magestad por el papel que será con ésta, y aunque yo me aprovecho dél en partes para lo que se ha de hazer en Constantinopla, como escrivo en otra carta que será con ésta, me ha parescido embiarle a Vuestra Magestad por ser el autor tal y para que si paresciere echar esta plática en los oydos del Rey de Fez, pueda hazerse" ${ }^{13}$. Y se añade un informe en italiano, manuscrito y firmado por Diego de Urrea. Este informe, así como las cartas que Urrea comienza a escribir poco después de su llegada a España, nos plantean un problema: Urrea escribe un buen italiano y un español perfecto, $y$ además lo hace con una caligrafía que evidencia la mano de una persona cultivada y agil en el manejo de la grafía latina. ¿Como se compagina este hecho con el que Urrea, que en este momento parece tener treinta años, hubiera sido cautivado cuando tenía tan sólo cinco o seis? A esta pregunta se le pueden dar varias respuestas. Por un lado, Urrea podría haber contado esta historia para que le fuera más fácil la reconciliación con la Iglesia Católica que, como "renegado", suponía su paso ante el Tribunal de la Inquisición ${ }^{14}$. Pero cabe también otra explicación: en una carta de 8 de abril de 1596, Bartolomé Leonardo de Argensola, que fue, como veremos, discípulo de Urrea, da la siguiente versión de la vida de éste: "Es Urrea de hasta quarenta años, italiano de nación, captivaron él y su madre siendo muy niño y él anduvo mucho tiempo con el Ochali muy su privado; salió doctísimo y llegó á ser Secretario del gran turco, muy estimado cuando él supo

12 Entre los fondos del Archivo General de Simancas (AGS), Estado, Venecia (Leg.1331, 55, año 1572) se conserva el ofrecimiento del coronel Moreto, calabrés, que quiere servir a España. No se puede comprobar que se tratara del padre de Diego de Urrea. Reitera en 1575 sus deseos de servir a España (Venecia. Leg. 1335, 37) y es designado en $1576(1335,11)$.

13 AGS, Estado, Sicilia, Leg. 1157, 25 de mayo de 1591.

14 Sobre este tipo de reconciliaciones, y las estrategias que seguían los "renegados" para ser readmitidos en el seno de la sociedad católica, se basa el libro de Bennassar, B., y L., Les chrétiens d'Allah: l'histoire extraordinaire des renégats au XVIème et XVIIème siècle, Paris, 1989. 
que era de nación cristiano, y por diligencias de su madre determinó de volver al camino de la verdad, y así huyó y llegado á Sicilia se baptizó, porque no lo estaba según él dize; sacóle de pila la virreyna de Sicilia condesa de Alba de Aliste que es hija del conde de Aranda, por lo qual se llamó Urrea [...]" ${ }^{15}$. En esta historia, transmitida sin duda por el propio Urrea, se dice que Urrea huyó, y no que fue capturado (como en otras versiones), y se alude también al cautiverio de su madre, hecho que podría explicar el que conociese bien el italiano a pesar de su temprana captura.

En el informe mencionado, Urrea da cuenta de cómo Uluŷ 'Alī está haciendo planes para conquistar el reino de Fez, que le interesa, entre otras cosas, por haberse enterado por boca del Moluco ('Abd al-Malik) de que allí hay facilidad para construir galeras. Urrea lo sabe bien, porque siendo él Morato Aga fue enviado a Marruecos como embajador para tratar de este tema (la república corsaria de Argel estaba en perpetua necesidad de madera y bastimentos para construir naves). Allí coincidió con el embajador español, el padre Diego Marín ${ }^{16}$, a quien al-Manșūr trató mejor que a él. En el mismo escrito cuenta que ha sido secretario durante trece años en Argel, Trípoli, Constantinopla y Túnez, y tiene muchos contactos (muchas "inteligencias") pues aún hoy, tras dos años en Palermo, se ha enterado del envío de dos embajadas turcas a Argel. Hasan Aga se ha casado con la viuda del Moluco del que tiene un hijo, Muley Ismāīil ${ }^{17}$. En Argelia, entre otros príncipes marroquíes, tuvo relación con Muley Xeque, como sabemos por una carta que, muchos años después, éste enviaría a Felipe III cuando se encontraba en Carmona negociando la entrega de Larache, y en la que decía: "Hago saber a Vuestra Magestad que Diego de Urrea, vuestro criado, se crió conmigo en Tremecén y estudiávamos juntos y el amor que me tenía en aquel tiempo lo tiene mucho más agora, que bien se echa de ver por las cosas que me des-

15 Conde de la Viñaza, Los cronistas de Aragón, ed. facsímil del original de 1904, Zaragoza, 1986, 95. En otra carta de 1595, Argensola decía que "Urrea no solamente era secretario del Turco y tenía todos los papeles de Persia y Esclavonia y de otras partes, mas en todo lo que toca a interpretaciones era el mayor, como tan docto en las lenguas, y así es grande su autoridad", id., 97.

16 Cabanelas, D., "Diego Marín, agente de Felipe II en Marruecos", Miscelánea de Estudios Árabes y Hebraicos, 21 (1972), 7-35. 1948.

17 Véase Oliver Asín, J., La hija de Agi Morato en la obra de Cervantes, Madrid, 
cubrió de los turcos y otras cosas" 18 . Urrea pues, reputado por gran letrado y conocedor de ciencias islámicas, se había educado en la madrasa de Tremecén.

No sabemos tampoco con exactitud en qué fecha vino Diego de Urrea a España, pero sin duda lo hizo acompañando el escrito antes mencionado de Alba de Liste de 1591, unos meses antes de que éste, por petición propia, abandonara el cargo de Virrey de Sicilia, o bien acompañándo a éste en su viaje de vuelta a España. Fue entonces nombrado Urrea, al amparo del conde Alba de Liste, que formaba parte del Consejo de Estado, profesor de árabe en la Universidad de Alcalá de Henares con salario de ciento veinte ducados. Éste no debía ser un trabajo muy estable o que exigiera gran dedicación, ya que el puesto dependía de que hubiera alumnos dispuestos a estudiarlo, y no tenemos noticias de que los hubiera. Con anterioridad a Diego de Urrea sólo sabemos de Alonso Zamora que fuera por algún tiempo profesor en Alcalá antes de ser trasladado a Salamanca ${ }^{19}$.

Urrea fue además intérprete de árabe para el tribunal de la Inquisición de Cuenca, aunque éste no debió ser un nombramiento estable, sino tareas que se le solicitaron en casos necesarios y concretos ${ }^{20}$. En Cuenca debió coincidir con Sebastián de Covarrubias, que pertenecía entonces al cabildo de la catedral de esta ciudad, pues éste le cita en la introducción a su Tesoro de la lengua castellana. Ya se ha visto que, para las etimologías árabes, Covarrubias consultaba varias fuentes, como las obras de Fray Francisco de Guadix, aunque se inclinaba por dar más autoridad a la opinión de Diego de Urrea, a quien consideraba como doctísimo en lengua árabe, como dice expresamente en varios lugares de su diccionario: "yo doy mucho crédito a Urrea, que sabe la lengua con mucho fundamento"; "ambos [referido a Francisco de Guadix] dicen una cosa, pero Urrea es en todo más doctrinal"; "pero en todo se debe dar crédito a Urrea, porque sabe la lengua ará-

${ }^{18}$ Carta de Muley Xeque a Felipe III, 12 de diciembre de 1609. AGS, Estado, Leg. 256,74

19 Bataillon, M., "L'arabe à Salamanque au temps de la Renaissance", Hespéris, 21 (1935), 16-17.

${ }^{20}$ Como tal figura en un proceso inquisitorial de 1597 conservado en el Archivo Diocesano Conquense, Leg. 208 n. $^{\circ}$ 2402, incoado al morisco Andrés Lebrero, de Arcos. Véase García-Arenal, M., Inquisición y moriscos. Los procesos del Tribunal de Cuenca, Madrid, 1978, 153. 
biga de raíz" ${ }^{21}$. Es de notar que todas las palabras árabes que Covarrubias toma de Urrea son transcritas con el sufijo causal de nominativo indeterminado, -un, lo que parece confirmar el buen conocimiento que Urrea tenía de la gramática del árabe clásico.

El 26 de octubre de 1595, García de Loaisa escribe una carta al Arzobispo de Granada respecto a los Libros encontrados en el Sacromonte y exige "que se llame a Arias Montano y al arábigo que tiene el conde de Alva de Liste y se ordenasse a cada uno de por sí que traduxessen dichos libros sin mostrarles la traductión que está hecha [la de Miguel de Luna y Alonso del Castillo] ni que el uno sepa del otro para que se vea si conforman las traductiones" ${ }^{22}$. En agosto de 1596, una real cédula de Felipe II ordena a Arias Montano y a Diego de Urrea que viniesen a Granada para "asistir a la traducción de ciertos libros - los famosos Libros Plúmbeos-y no salgan della sin licencia del arzobispo" 23 . En una carta del mismo fondo se dice que este arábigo del conde Alba de Liste es Diego de Urrea, "cathedrático de Árabe en la Universidad de Alcalá, yntérprete de Nuestro Señor" 24.

Por entonces, marzo de 1596, Miguel de Luna dice que lleva casi un año traduciendo los libros y que aún le quedan unos dos años de trabajo, y pide ayuda de costa, que se le dé el oficio de veedor de obras reales de la Alhambra porque tiene muchos gastos y suplica que se le envíen ciertos libros de El Escorial que le hacen mucha falta ${ }^{25}$. No es el único que pide aumento de sueldo: Urrea tuvo problemas con el arzobispo Pedro de Castro, pues al parecer sus traducciones no coincidían con la manera en la que el arzobispo quería presentar los textos, y en ocasiones le pidió que variara la traducción a cambio de aumentos de salario. Estos aumentos se produjeron, pero ambos acabaron peleándo$\mathrm{se}^{26}$. Está claro que los traductores preferidos de Pedro de Castro eran

${ }^{21}$ Covarrubias, S. de, Tesoro de la lengua castellana o española, ed. Felipe C.R. Maldonado, revisada por Manuel Camarero, Madrid, 1994, 41, 68, 78.

${ }^{22}$ Archivo de Zabálburu. Altamira, D.109

23 Apud Cabanelas, El morisco granadino Alonso del Castillo, 194, n.1.

${ }^{24}$ Zabálburu, Altamira 161, D.110. García de Loaisa dice que los tres, Luna, Castillo y Urrea, son muy doctos, "pero tengo por más docto al Castillo, y ansí convendrá ver su traslación".

${ }^{25}$ Zabálburu, Altamira 161, D. 133 y 134.

${ }^{26}$ Según correspondencia incluida en los Leg. III y IV de la Abadía del Sacromonte, sobre los que M. Hagerty se basa en su "Traducción y sobornos en la corte de Felipe II. El caso del catedrático Diego de Urrea y el arzobispo Pedro de Castro", texto inédito de una conferencia que agradecemos al autor nos haya permitido utilizar. Véase también 
Luna y Castillo. En 1596, Pedro de Castro escribe al rey pidiendo gratificación para Miguel de Luna y Alonso del Castillo, que hacían un trabajo utilísimo y muy difícil porque los libros estaban en un árabe que no era el vulgar que entonces se usaba, lo que parecía implicar que Urrea no sabía más que, precisamente, ese árabe vulgar, cosa que, como sabemos, no era cierta ${ }^{27}$. Ya hemos visto que, según todos los indicios, Urrea poseía un alto conocimiento del árabe clásico y de su gramática. Disponemos ahora, además, del texto de numerosas cartas procedentes de la cancillería marroquí escritas en una complicada prosa rimada que Urrea tradujo, demostrando tales conocimientos ${ }^{28}$. Probablemente el disgusto de Pedro de Castro estaba causado porque Diego de Urrea (como Arias Montano, que se había retirado) no consideraba que los Libros Plúmbeos fuera auténticos ${ }^{29}$. Así lo afirma el historiador Luis Tribaldos de Toledo en una carta dirigida al Marqués de Estepa en febrero de 1633. En ella, Tribaldos, que considera que los Plomos son falsificaciones, menciona en apoyo de sus argumentos a aquellos que han sido de su misma opinión, entre ellos: "Traté más de quinze o veinte años familiarísimamente a Diego de Urrea, grande Arábigo y que fue intérprete de esa lengua de su Magestad, y fue a Granada a la Versión de las Láminas, y después de aver buelto de Nápoles enfermo a esta corte, me dixo muchas vezes lo que antes avía callado, y es que quando le interpretava [al arzobispo] lo que las láminas dezían puntualmente, en hallando una mala doctrina de mahometanismo, que las avía muchas, el Arzobispo se enfadava con él y dezía que no lo entendía, ni era posible que aquello dixesen, y él le dava el sentido que benía bien para que pareziesse Cathólica, cosa que Urrea nunca tuvo por tal, aunque llevado del interés, disimuló al fin, correspondiendo con el gusto del Arzobispo, pero con bien poca conciencia" ${ }^{30}$. Informado, sin duda, por

Hagerty, M., "La traducción interesada: el caso del Marqués de Estepa y los libros plúmbeos", Homenaje al Prof. Jacinto Bosch Vilá, Granada, 1991, vol. II, 1179-1186.

${ }^{27}$ Zabálburu, Altamira, 161. D.135, Carta de Pedro de Castro al Rey de 12 de marzo de 1596.

${ }^{28}$ Cartas y traducciones editadas en García-Arenal, M., Rodríguez Mediano, F., y El Hour, R., Cartas marruecas. Documentos de Marruecos en archivos españoles (ss. XVI-XVII), Madrid, CSIC, 2002.

29 Cabanelas, D., "Arias Montano y los libros plúmbeos de Granada”, Miscelánea de Estudios Arabes y Hebraicos, XVIII-XIX (1969-70), 7-41.

${ }^{30}$ Harvey, P., y Wiegers, G.A., "The Translation from Arabic of the Sacromonte Tablets and the Archbishop of Granada: an illuminating correspondence", Qurțba 1 (1996), 65. 
el propio Urrea, Lupercio Leonardo de Argensola escribía: "Yo lo tengo por burlería esto de las láminas, y con más fundamento que tuvo Çurita para tener por tal la campana de Velilla: el Arçobispo de Granada ha dado en esta piedad y esfuérçala y concurren algunos sirviendo más a su (está cortado el papel) que á la verdad" ${ }^{31}$. Ignacio de las Casas, un jesuita de origen morisco que participó también en el asunto de los Plomos ${ }^{32}$, dice en cartas al Arzobispo de Granada que tiene información de que Castro acompañaba constantemente la tarea de los intérpretes, y que "desmenuza las palabras" y les "ba haciendo tales y tantas preguntas que viene a lo que se desea", es decir, que condiciona a los traductores para hacerles decir lo que él quiere. El Arzobispo a su vez dice que no está satisfecho con ninguno de los intérpretes pues "el de Alcalá (es decir, Diego de Urrea) no ha acertado a leer letra ni interpretado cosa de momento, y el licenciado Luna, con ser buen letrado, hábil y suficiente en las dos lenguas Arábiga y Castellana no se fía por tener entendido que no sabe la grammatica Arabiga [...] y el licenciado Castillo [...] sabe más la lengua que los demás y sabe la latina y castellana medianamente [...] pero dexado solo diría disparates" ${ }^{33}$. En el Archivo del Sacromonte se conserva una especie de índice de los trabajos de traducción realizados por Miguel de Luna, Diego de Urrea, el licenciado Alonso del Castillo, con breves aclaraciones acerca de las principales características de dichos traslados ${ }^{34}$. En la Biblioteca Lázaro Galdiano de Madrid se conservan copias escritas en árabe cursivo de varios Libros Plúmbeos, copiados del original escrito en caracteres "salomónicos" y certificados por Miguel de Luna y Diego de Urrea, así como traducciones, firmadas por el mismo en octubre de $1596{ }^{35}$, que prueban ampliamente que Diego de Urrea acertaba a "leer letra" y a interpretarla aunque no quizá a gusto del Arzobispo. El trabajo lo debía estar para entonces realizando en Madrid: a finales de 1597, el agente del arzobispo en la Corte, Jerónimo de Herrera, le informa a aquél de que Urrea se queja de lo costoso que le está resultando el trabajo. Cas-

\footnotetext{
31 Carta de Lupercio Leonardo de Argensola, 22 de septiembre de 1598, Conde de Velilla, Los cronistas de Aragón, 77.

32 Véase el artículo de R. Benítez Sánchez-Blanco en este mismo volumen.

33 Correspondencia de Ignacio de las Casas con el Arzobispo de Granada y con la general Inquisición sobre el negocio del Sacromonte. British Library, Add. 20915, vol.I, f. 73 y $77 \mathrm{r}$.

${ }^{34}$ Cabanelas, El morisco granadino Alonso del Castillo, 214-15.

${ }^{35}$ Lázaro Galdiano, Papeles de José Temprado, n. ${ }^{\circ} 506$.
} 
tro responde a vuelta de correo diciendo que debe ganar a Urrea a la "causa" de los Libros Plúmbeos "a cualquier precio" ${ }^{36}$. En enero de 1598, Herrera informa a Castro de lo que ha gastado hasta ahora para mantener contento a Urrea ${ }^{37}$. Urrea debió por entonces abandonar el asunto de los Plomos, o lo quitaron.

Según el propio Diego de Urrea cuenta en un memorial dirigido a Felipe III ${ }^{38}$, en 1598 , poco antes de su muerte, Felipe II le llamó al Escorial para que enseñara árabe a algunos religiosos del monasterio, y allí realizó también un catálogo de los manuscritos árabes de su biblioteca, además de confeccionar un Vocabulario Arábigo para uso de sus estudiantes. En el memorial citado reitera su conocimiento de las lenguas árabe, turca, persa y tártara, por haber sido muchos años secretario del Gran Turco en Persia y en África ("por lo cual podría dar orden y traça cómo con facilidad la África viniese en poder de Su Magestad") y pide al Rey que le aumente el salario pues no tiene otra forma de vida.

Efectivamente, Urrea realizó un catálogo bilingüe árabe-castellano, publicado por Morata en el artículo citado, de los fondos árabes antiguos de El Escorial, en el que se describen 449 obras árabes ${ }^{39}$. Este catálogo y su tarea entre los frailes de El Escorial debió dejar bien sentada su consideración profesional. En el Memorial dirigido a Felipe III, también publicado por Morata, Urrea afirma que deja cuatro frailes muy doctos en la lengua árabe que pueden además certificar que el propio Urrea, además de la lengua, conoce bien diversas ciencias islámicas, y pide que el rey le ampare y le dé tarea y salario. Efectivamente, fue nombrado intérprete oficial de árabe y de turco por Felipe III.

Sabemos también que, hacia final de esta década, Urrea enseñó privadamente, durante algún tiempo, la lengua árabe a los hermanos Bartolomé y Lupercio Leonardo Argensola ("quiere hazernos grandes arábigos"); este último, en concreto, deseaba investigar la Edad Media aragonesa ${ }^{40}$. Como Urrea disponía de tiempo, se había puesto a

\footnotetext{
36 Abadía del Sacromonte, leg. III n. 97/342. Apud Hagerty "Traducción y sobornos".

37 Abadía del Sacromonte, leg. III, 106/359. Apud Hagerty, "Traducción y sobornos".

${ }^{38}$ Publicado por Morata, N., "Un catálogo de los fondos árabes primitivos de El Escorial", Al-Andalus, II (1934), 102-103.

39 Véase también Justel, B., La Biblioteca de El Escorial, Madrid, 1978, 221.

40 Green, O.H., Vida y obras de Lupercio Leonardo de Argensola, Zaragoza, 1945, 53; Márquez Villanueva, F., El problema morisco (desde otras laderas), Madrid, 1991, 60 n. 18.
} 
preparar una historia de la dominación islámica en España a base de fuentes árabes, para deshacer los errores de otras historias, como cuenta Bartolomé Leonardo de Argensola: "[Urrea] se burla casi de cuantos historiadores tenemos que traduzen en castellano y uno de ellos es Blancas, que dice que Muza quiere dezir christiano y del Padre Mariana en mil partes, y él advierte, que así como en Europa aprendemos la lengua latina para saber por medio della las cosas de la religión y las demás de la vida, ansí en Asia y África los que siguen a Mahoma aprenden la arábiga verdadera que se hablaba en la invasión de España y se perdió como la latina" ${ }^{41}$. Así pues, Urrea criticaba historias como la de Jerónimo de Blancas o la del Padre Mariana, basándose en su propio conocimiento de la lengua árabe y de la cultura musulmana. Sin embargo, con quien más crítico se mostraba era con Miguel de Luna y su Historia verdadera del Rey Don Rodrigo. El propio Argensola escribía: "[...] el libro [...] de la perdición de España [...] estoy cierto de que sentirá dél lo siguiente que aunque su autor dize que es historia verdadera traduzida de arábigo, se echa de ver su famosa mentira é invención despropositada, á lo menos en consideración de historia, y hase echado á perder poniendo por las márgenes los vocablos arábigos que traduze, porque él vino á esta corte donde luego se topó con Urrea, el qual lo cogió en ochocientas mentiras con que lo confundió" "42. Urrea y Luna, como se ha visto, trabajaron juntos en la traducción de los Plomos del Sacromonte, y a juzgar por ésta y otras noticias, la opinión que aquél tenía sobre éste y su historia era bastante mala, y, además, estaba bien fundamentada: “[...] Urrea, á quien ahora vuelve el Rey á enviar a Granada para acabar la averiguación de los Stos., nos contó á Lupercio y á mí cómo confundió al que se llama intérprete de este libro; porque después de haberle dicho que no sabía arábigo y ser disparate y mentira quanto él pone por las márgenes y bernardina que dizen por acá, le preguntó que dónde estaban los originales del libro, respondió que en el Escorial, y como Urrea es quien por el Rey ha ordenado y reconocido los libros del Escorial y sabe que allí no hay tal libro le probó la mentira, no sin risa de toda España, por donde esto se ha entendido" ${ }^{43}$. Por el contrario, la histo-

\footnotetext{
41 Carta de Bartolomé Lupercio de Argensola, 6 de mayo de 1597, Conde de la Viñaza, Los cronistas de Aragón, 97.

42 Carta de Bartolomé Leonardo de Argensola, 8 de abril de 1596, id., 95.

43 Carta de Bartolomé Leonardo de Argensola, 6 de mayo de 1597, id., 97.
} 
ria que estaba preparando el propio Urrea se fundamentaba en su buen conocimiento del árabe y de las fuentes, a diferencia de Miguel de Luna, como explicaba el propio Argensola: "el mismo Urrea tiene hecha la primera y segunda parte, digo traduzida de esta misma historia de España desde que se ganó, por los Árabes y Maurusíes; la división della en régulos fué causa de menguar sus fuerças, y aunque él lamenta mucho la librería que dexó en Constantinopla, está éste su libro sacado de las Chronicas que guarda el turco y el rey de Marruecos: están ahora en poder del Secretario Francisco Idiáquez para dar licencia para la impresión [...]" 44 . Como se ve, la historia de Urrea estaba acabada y, sin embargo, lamentablemente, no llegó a publicarse, y el original, hasta hoy, se desconoce. En el mismo lugar, Argensola habla aún de otra traducción de Urrea: "El rey nuestro Sr. lo entretiene leyendo lenguas en la Universidad de Alcalá, y estos días le ha traducido á su merced un libro Arábigo de la librería del Escorial, en que el autor moro trata de exemplos de hombres virtuosos y pone entre ellos á Jesucristo nuestro Señor, casi tratando dél como Josepho" ${ }^{45}$.

Con el tiempo, al parecer, Urrea se cansó de vivir en Madrid, e incluso tenemos referencias de que intentó volver a Nápoles. En marzo de 1607, Felipe III escribe al Duque de Medina Sidonia una carta que le lleva el propio Urrea en la que dice: "Diego de Urrea que ésta os dará me ha servido muchos años en esta Corte de intérprete de las lenguas arábiga, turquesca y persiana con particular satisfacción, y ha enseñado la arábiga y turquesca a una persona que traduzirá como convenga las cartas que vinieren de aquellas partes, y aviéndome significado que por esto no podrá hazer falta en esta corte de más de que se alla en ella con poca salud y el desseo que tiene de residir en Málaga y essa costa a vuestra orden, donde podrá ser de mucho serviçio por la expiriencia que tiene de las cossas de África y Turquía y las inteligencias que allí tendrá, he tenido por bien de condescender con su desseo y mandado que se le continúe aquí la paga de su sueldo". Urrea residirá, pues, en Málaga, pero a disposición del Duque para hacer lo que éste ordenare o acudir adonde se considerase hacía falta. El rey insistía en que el Duque debía procurar sacar mucho fruto de sus inteligencias, es decir, de los espías e informadores que tenía Urrea, "y le tendréys por muy encomendado para honrarle y favore-

\footnotetext{
${ }^{44}$ Carta de Bartolomé Leonardo de Argensola, 8 de abril de 1596, id., 95.

45 Ibid.
} 
cerle en todo como lo merece su persona por lo mucho y bien que me ha servido, el zelo que tiene de continuarlo y sus buenas partes, que de ello receviré de vos particular gusto y servicio" ${ }^{46}$.

Así pues, a partir de 1607, Urrea pasa a residir en el sur de España y estar a las órdenes del Duque de Medina Sidonia. Parece que en esos años tuvo el proyecto de regresar al reino de Nápoles, pero el Duque le destinó al asunto de Larache en 1609. Diego de Urrea se trasladó a Carmona y más tarde a Tánger y a Cádiz para ocuparse de la negociación ${ }^{47}$. No es cuestión de volver aquí al asunto de la cesión de Larache ${ }^{48}$, tan sólo recordaremos brevemente que éste había sido ya un objeto de negociación entre Felipe II y Aḥmad al-Mansuūr. A la muerte de éste, a finales de 1603, estalló una guerra civil entre sus hijos y herederos, de los cuales los candidatos más importantes fueron Muley Zaydān, que controlaba la zona de Marrakech, y Muley al-Šayj (Muley Xeque), que dominaba el Norte del país con capital en Fez. Zaydān era el candidato al que apoyaban los turcos, y Muley Xeque estableció alianzas con España. Muley Zaydān conquistó Fez por un breve período de tiempo en 1608, lo cual obligó a Muley Xeque a refugiarse en Larache y, desde allí, pasar a la Península, donde estuvo alojado en Carmona, mientras negociaba ayuda económica y militar española para recuperar su reino a cambio de ceder la plaza de Larache a los españoles, cosa que se llevó a cabo en 1610.

En cuanto Muley Xeque llegó a Andalucía, se destinó a Urrea para que hiciera de intérprete e intermediario en estas cuestiones. Urrea no sólo conocía de antiguo a Muley Xeque, de quien, hemos visto, había sido condiscípulo, sino que se lo ganó informándole, como había hecho con los españoles, de los planes turcos sobre el reino de Fez ${ }^{49}$. En Carmona, donde formó parte de su séquito, le tradujo a Muley Xeque los 16 apuntamientos de la negociación de Larache llevados por Juanetin Mortara ${ }^{50}$, y acompañó al candidato marroquí en su regreso a Marrue-

46 Archivo Ducal de Medina Sidonia, Leg. 2407, Carta del rey al Duque, de Madrid, a 12 de marzo de 1607.

47 AGS, Estado, Leg. 256. Los n. ${ }^{\circ} 81$ a 86 de este legajo contienen informes manuscritos de Urrea sobre la marcha de los asuntos de Berbería.

48 Hemos dedicado a esta cuestión un estudio detallado en García-Arenal, M., Rodríguez Mediano, F., y El Hour, R., Cartas marruecas. La participación de Diego de Urrea se encuentra desarrollada en 95-127.

49 AGS, Estado, Leg. 2638, 20 diciembre 1609.

50 AGS, Estado, Leg. 213. 
cos, estando con él en el Peñón de Vélez, y viajando también a Tánger.

Pedro de Castro, en su perpetuo esfuerzo por buscar traductores que le fueran apropiados, es decir, que dieran la versión de los Plomos que a él le convenía, buscó en el séquito moro de Muley Xeque quien pudiera ayudarle. En su correspondencia con Tribaldos, el marqués de Estepa dice de los Plomos del Sacromonte: "están tan lejos de ser mahometanos estos libros que poniendo yo aquí a un moro diestro en la lengua, aviéndolo comenzado a leer y entender, lo arrojó, diziendo que eran cosas de Christianos. Y lo mismo hizieron en tiempo del Arçobispo [Pedro de Castro] otros moros que vinieron con el Rey Muley Xeque cuando estuvo en Carmona" ${ }^{51}$. Estos moros encontraban que el texto estaba trufado de "cosas de christianos": Diego de Urrea y Marco Obelio Citaroni, a quien ya hemos citado y de quien hablaremos a continuación, encontraban, en cambio, que estaban llenos de doctrinas musulmanes, lo cual les hizo caer en desgracia con el Arzobispo.

La estancia en Carmona y la negociación de Larache parecen haber sido las dos últimas tareas de Urrea. El último documento que de él hemos encontrado está fechado en Cádiz en julio de 1610 y dice "estoy sirviendo en Cádiz en las traducciones de las cartas que del rey moro vienen, y responder a las dichas en lengua arábiga" 52. Muley Xeque murió en 1613 y no hemos encontrado más noticias de Urrea con posterioridad a esta fecha. Desconocemos asimismo la fecha de su muerte. Cabe la posibilidad de que regresara a El Escorial o que, por fin, volviera a Nápoles. Un memorial conservado entre los fondos del Consejo de Estado de 1623 presentado por otro traductor de los Plomos, italiano esta vez, que quiere ocupar su plaza en la Biblioteca de El Escorial, se refiere a él como Ludovico de Urrea, no sabemos si por error o porque fuera éste el nombre que usara en italiano. El documento es el siguiente:

"Vuesa Magestad fue servido de remitir al Consejo un memorial de Marco Obelio Citaroni en que reffiere que ha servido a la sede Apostólica catorze años de intérprete y Cathedrático con otros cargos. Que quando vino el Arzobispo de Granada que agora lo es de Sevilla

${ }^{51}$ Apud Harvey y Wiegers, "The Translation from Arabic of the Sacromonte Tablets", 69

${ }^{52}$ AGS, Estado, Leg. 256 n. ${ }^{\circ} 86$. 
a esta corte, suplicó a Su Magestad que esté en el cielo, mandase buscar un intérprete que supiese perfectamente la lengua Arábiga para traducir las láminas y libros que hallaron en el Monte de Granada y Su Magestad mandó hazer una junta de donde resultó escrivir a Roma y otras partes para hazer diligencia de buscar persona que las supiese declarar. Que hallándose en aquella corte ocupado con 700 ducados de salario de más de sus provechos y mayores expectatibas, de parte de Su Magestad y del dicho Arzovispo le persuadieron a que viniese a ynterpretar las dichas láminas poniéndoselo por cargo de conciencia y prometiéndole recompensa doble, y haviendo llegado a Granada, comenzó su ynterpretación y después passó a Sevilla con el dicho Arzobispo seguiendo su declaración, y porque halló ser falsas las láminas y cossa de tanta importancia en detrimento de Nuestra Santa Fee, dixo su parezer no queriendo anteponer su provecho a la verdad, por ser los dichos libros apóchrifos, llenos de frases y sentencias del Alcorán y de dotrina de Mahometanos mezclada con la nuestra. Ni el estilo, frases, lengua ni caracteres, correspondía con ningún autor Árabe christiano ni mahometano, porque antes que Mahoma predicase su falsa seta huvo en el oriente y medio día Christianos y hombres doctos, y echó de ver que el autor de las dichas láminas era algún morisco ygnorante. Que porque dixo esta Verdad al dicho Arzovispo le mandó salir de su cassa con escussa de que no podía atender a la tradución, y después le ha contradicho en sus pretensiones, de modo que queda perdido y destruydo y suplica a Vuestra Magestad humildemente que teniendo consideración a lo dicho y a que en la Librería de San Lorenzo ay más de 600 libros de historias y es importante su tradución, le haga merced de una de las dos plazas que vacaron por Ludovico de Urrea y Francisco de Gurmendi que llevaban entre ambos tres mill ducados al año y este suplicante se contentará con un salario moderado con que poder pasar conforme a su calidad.

- Al Consejo ha parecido que sería bien escrivir al Arzobispo de Sevilla avisse lo que siente deste ombre y lo que sabe dél, y si por su parte se le hizo instancia para que viniese a España.

- El Marques de Montesclaros: que si este ombre es plático en las lenguas que dize sería muy útil el admitirle, y que se hiziese alguna diligencia más apretada que la de escrivir al Arzobispo, pues es de creer que no informará muy en su favor, y que en Sevilla ay un frayle conocido del Marqués muy prático de la lengua Arábiga y se le podría remitir para que lo examine. 
Vuestra Magestad mandará lo que mas fuese servido. En Madrid, a 10 de enero de 1623 " 53.

Citaroni, pues, no había respondido, como tantos otros, a las expectativas del Arzobispo, quien no había dudado en prescindir de sus servicios, y solicitaba ahora se le diese trabajo en la Biblioteca de El Escorial. Ésta, además, acababa de incrementar muy notablemente sus fondos árabes: en 1612 el almirante Fajardo capturó, a la altura del puerto marroquí de Salé, unas naves que contenían bienes personales de Muley Zaydān, entre ellos y sobre todo, la biblioteca privada de su padre que contenía unos cuatro mil volúmenes. En marzo de 1614, el prior de El Escorial, Juan de Peralta, pidió que le dejasen en depósito los libros a la biblioteca del convento. Tras consultar a su confesor acerca de si estos libros constituían un atentado contra la fe, Felipe III los donó a la Biblioteca de El Escorial donde aún hoy se conservan ${ }^{54}$. La carrera de Citaroni, parece, en ciertos aspectos, un calco de la de Urrea, o de la de otros traductores contemporáneos, implicados en actividades inmediatas de traducción e interpretación, y también en tareas académicas, de la traducción de los Plomos del Sacromonte a la catalogación de la Biblioteca de El Escorial, o a la composición de obras sobre la historia de los árabes en la península Ibérica. En la medida en que se trata de una figura paradigmática, la carrera de Diego de Urrea nos da las claves de una actividad que se desarrollaba a menudo en los intersticios de un mundo fronterizo, cuya precariedad determinaba profundamente los destinos vitales de sus protagonistas, pero a la vez sentaba las bases de un conocimiento fundado en una visión nueva de un mundo en expansión.

\section{RESUMEN}

En este artículo tratamos de reconstruir la vida de Diego de Urrea, uno de los traductores e intérpretes de árabe más importantes de finales del s. XVI y principios del XVII en España. Sus actividades como catedrático en Alcalá de Henares, traductor de los Plomos del Sacromonte, catalogador de los manuscritos árabes de El Escorial, negociador, intermediario y espía en asuntos marroquíes, hacen de él una figura paradigmática de lo que significó en su época

53 AGS, Estado, Leg. 2645.

54 Aunque fueron diezmados por un incendio en el s. XVII. Sobre todo ello véase Justel, B., La Real Biblioteca de El Escorial y sus manuscritos árabes. 
el conocimiento y la utilización del árabe, como instrumento para cuestiones de importancia política y estratégica inmediata y también en su dimensión humanística y académica.

\begin{abstract}
This article is dedicated to the life and work of Diego de Urrea, one of the most important translators and interpreters of Arabic in late 16th-17th century Spain. He was a professor of Arabic at the University of Alcalá de Henares and a translator of the Sacromonte Lead Tablets. He catalogued the Arabic manuscripts of the Library at El Escorial, where he also taught the friars and translated Arabic works. He was an interpreter, negotiator and spy in affairs related to Morocco. His career illustrates what the knowledge and use of the Arabic language as an instrument of political and strategic matters meant in his age, as well as illuminating Arabic's academic and humanistic dimension.
\end{abstract}

